\title{
Modifications of the Response of Materials to Shock Loading by Age Hardening
}

\begin{abstract}
JEREMY C.F. MILLETT
The shock response of two age-hardened alloys, aluminum 6061 and copper- 2 wt pct beryllium $(\mathrm{CuBe})$, has been investigated in terms of their microstructual state; either solution treated or age hardened. While age hardening induces large increases in strength at quasi-static strain rates, age hardening does not produce the same magnitude of strength increase during shock loading. Examination of the shocked microstructures (of 6061) indicates that the presence of a fine distribution of precipitates throughout the microstructure hinders the motion and generation of dislocations and hence reduces the strain-rate sensitivity of the aged material, thus allowing the properties of the solution-treated state to approach those of the aged. It has also been observed that the shear strength of solution-treated $\mathrm{CuBe}$ is near identical to that of pure copper. It is suggested that this is the result of two competing processes; large lattice strains as beryllium substitutes onto the copper lattice inducing a high degree of solution strengthening acting against a reduction in shear strength caused by twinning in the alloy.
\end{abstract}

DOI: $10.1007 / \mathrm{s} 11661-014-2571-\mathrm{z}$

(C) Published with permission of the British Crown 2014

\section{INTRODUCTION}

THE response of materials to high velocity impact scenarios is of interest to a number of industries, including armor and armor defeat applications from the military, and satellite protection. However, to gain an understanding of materials response under these conditions is nearly impossible given the complex nature of the strain state under the impact site. Therefore, it is more usual to generate the appropriate strain rates under conditions where the resultant state of strain is precisely known. In general, the technique of plate impact is employed, where the impact of a flat flyer plate onto an equally flat target assembly generates a planar shock front, behind which conditions of one-dimensional strain apply (i.e., all strain is accommodated along the impact axis). Further discussion of the basics of shock compression is beyond the scope of this report, but the interested reader is directed to the text books of Meyers $^{[1]}$ and Bourne. ${ }^{[2]}$

The mechanical response of materials within the weak shock regime (i.e., below the pressure where the shock velocity $\left(U_{\mathrm{S}}\right)$ becomes greater than the ambient pressure elastic sound speed $\left(c_{\mathrm{L}}\right)$ ), like lower strain-rate loading, is governed by the material microstructure. This will include crystalline structure, grain size, distribution, and balance of additional phases and prior history (dislocation and twin density). The most widely understood class of materials under shock loading conditions is the face-centered cubic (fcc) metals and alloys (mentioned here as they are the base metals for the alloys under

JEREMY C. F. MILLETT, Senior Scientist, is with AWE, Aldermaston, Reading RG7 4PR. U.K. Contact e-mail: Jeremy.millett (a) awe.co.uk

Manuscript submitted April 28, 2014.

Article published online September 26, 2014 investigation in this report). With no other factors such as additional phases, the mechanical response of these materials is driven by the stacking fault energy $($ SFE $-\gamma)$, which controls the motion and generation of dislocations. The operative slip system in this case is $\mathrm{a} / 2\langle 110\rangle$ dislocations, slipping on the $\{111\}$ planes. However, it is often energetically favorable for the unit dislocation to split into two partials, of type a/6 6112$\rangle$. The stacking fault energy controls the separation distance $d$ of these partials:

$$
d=\frac{\mu a^{2}}{24 \pi \gamma}
$$

where $\mu$ is the shear modulus and $a$ is the lattice parameter. As the partials must move as a pair, it is clear that increasing their separation (by reducing the stacking fault energy) will impede their ability to overcome obstacles, either by cross-slip or by climb, potentially to the point where dislocation activity may be replaced by other mechanisms of plasticity such as twinning. In the case of metals with moderate or high stacking fault energies, (copper ca. $80 \mathrm{~mJ} \mathrm{~m}^{-2}$, aluminum ca. $135 \mathrm{~mJ} \mathrm{~m}^{-2}$, and nickel ca. $\left.200 \mathrm{~mJ} \mathrm{~m}^{-2}\right),{ }^{[3]}$ recovered microstructures have been seen to consist largely of welldeveloped dislocation cells, ${ }^{[4]}$ along with vacancy loops observed in pure aluminum. ${ }^{[5]}$ In addition, the post-shock mechanical response in at least pure copper ${ }^{[4]}$ and nickel ${ }^{[6]}$ has shown a significant increase in strength (when compared to the undeformed material), again explained in terms of rapid increases in dislocation density. In terms of in situ shock measurements, the shear strength in pure nickel ${ }^{[8]}$ has been observed to increase over a period of ca. $500 \mathrm{~ns}$ behind the shock front; a similar time period was noted by Murr and Kuhlmann-Wilsdorf ${ }^{[9]}$ for the shocked microstructure (in nickel) to reach its steady configuration. However, 
changing the stacking fault energy by simple alloying has been shown to have a profound effect upon the shock response. In a series of articles, Rohatgi and his colleagues $^{[10-12]}$ showed that increasing the aluminum content in copper, to a maximum of $6 \mathrm{wt}$ pct caused a significant reduction in stacking fault energy, from $78 \mathrm{~mJ} \mathrm{~m}^{-2}$ in pure copper to $6 \mathrm{~mJ} \mathrm{~m}^{-2}$ in copper$6 \mathrm{wt}$ pct aluminum. Correspondingly, the shocked microstructure was observed to shift from one of dislocation generation to one controlled to large extent by twinning. The post-shock mechanical properties were similarly affected, with significant post-shock hardening in the pure copper, to no hardening at all in the most alloyed material. Similar observations have also been made in other low stacking fault energy fcc alloys such as austenitic stainless steels. ${ }^{[13,14]}$ Investigations of the shear strength behind the shock front and its variation with stacking fault energy have also been made. In a nickel-60 wt pet cobalt alloy, it was shown that the shock-induced shear strength was significantly lower than in nickel shocked to equivalent pressures. ${ }^{[8]}$ Recovered microstructures were shown to display a significant density of twins. It was also observed that the shear strength in a shock-loaded austenitic stainless steel was also near constant, rather than showing an increase behind the shock front as well. ${ }^{[15]}$ It was thus suggested that twinning had little contribution to either in situ or post-shock strength, again influenced by the role of stacking fault energy on dislocation motion and generation.

However, microstructural and mechanical responses to external loading can also be affected by the internal balance of additional phases. Murr et al. ${ }^{[16]}$ demonstrated that a fine distribution of thoria particles throughout an otherwise pure nickel shifted the shocked microstructure away from the expected dislocation cell structure, to one where the distribution of dislocations was much more random. Another (industrially) important way of producing such a microstructure is through age hardening, whereby fine intermetallic particles are dispersed throughout the microstructure by a low temperature heat treatment from a supersaturated solid solution. The effects on mechanical response have been studied extensively at quasi-static strain rates, but less work has been performed using shock loading techniques. Much of the work that has been performed has concentrated on aluminum alloys (mostly aluminum $6061)^{[17-23]}$ although a limited set of work has also been presented upon copper-beryllium alloys as well. ${ }^{[24]} \mathrm{In}$ the case of 6061 in the solution-treated (T0) condition, Gray ${ }^{[25]}$ showed that the shocked microstructure consisted of dislocation cells, much the same as copper or nickel. No post-shock mechanical tests were performed, but it would be expected that as with copper and nickel, significant post-shock hardening would be observed. In contrast, in the fully hardened T6 state, the same experiments revealed that the presence of fine $\mathrm{Mg}_{2} \mathrm{Si}$ precipitates resulted in a much more randomized dislocation structure, along with some planar slip. Postshock mechanical testing showed that there was no postshock hardening, suggesting that dislocation motion and generation had been greatly impeded by the presence of these precipitates.

In a series of articles, the effects of age hardening on the aluminum alloy $6061^{[26]}$ and a copper-2 wt pct beryllium alloy ${ }^{[27]}$ have been investigated. It is the intention of this article to bring the reported results together such that greater insights into the effects of age hardening on the shock response of materials can be gained.

\section{EXPERIMENTAL}

All experiments were performed using a range of single-stage gas launchers. Three types of experiment were performed, spallation (or dynamic tension), shear strength measurement, and soft recovery. The basic specimen geometry consists of a flat plate, with impact and rear surfaces flat and parallel to less than $5 \mu \mathrm{m}$. To ensure a planar shock front, the flyer plate is flat and parallel to the same tolerances, and at impact is aligned to the target to less than 1 milli-radian. Different experiments require different diagnostics and assembly techniques, and each experiment will be described in turn, along with the relevant diagnostics.

\section{A. Spallation}

This is the measurement of the shock-induced dynamic tensile strength of a material. This relies on the interaction of release waves from the rear of the target and flyer plates, which can potentially take the material in the region of that interaction into net tension. If that tension exceeds the tensile strength of the material, then the material can fail. This manifests itself as a reload signal after the main shock has started to release. Matters are simplified by matching the flyer material to that of the target (or at least making them closely related). The location of the spall location is controlled by the relative thicknesses of the flyer and target plates. This behaviour is monitored either by free surface velocimetry, using photon displacement velocimetry $(\mathrm{HetV}),{ }^{[28]}$ or through the use of a manganin stress gage, supported on the back of the specimen plate with a low impedance material. Generally, this is polymethyl methacrylate, chosen as its shock response has been well characterized, due to its use as a window material, ${ }^{[29]}$ and that it also has a close impedance match to the epoxy resins used in target assembly. The laserbased HetV technique ${ }^{[28]}$ was used in the copperberyllium experiments. $5-\mathrm{mm}$ plates of $\mathrm{CuBe}$ were impacted with either 3.2-mm flyer plates of aluminum $5083-\mathrm{H} 32$ or $2.6-\mathrm{mm}$ copper at velocities of 193 to $750 \mathrm{~m} \mathrm{~s}^{-1}$, to induce longitudinal stresses of ca. 2 to $15 \mathrm{GPa}$. Calculations of flyer plate thickness were made using a simple elastic wave speed assumption in both flyer and target materials, designed to place the spall plane in the center of the target plate. Note that the slight differences in wave speed between $\mathrm{CuBe}$ and copper (see Table II) result in the copper flyer being slightly thicker than half the thickness of the target. 


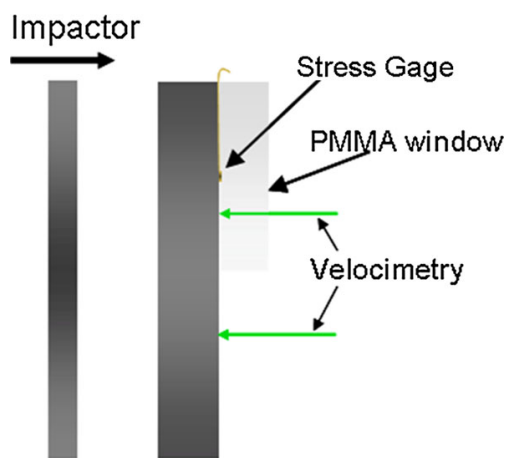

Fig. 1-Schematic representation of spallation target and flyer, showing configuration for both stress gages and velocimetry.

A schematic of a typical spall experiment is shown in Figure 1.

\section{B. Shear Strength Measurements}

The shear strength $(\tau)$ behind the shock front is an important parameter as it is one of the major factors that control materials' resistance to ballistic attack. ${ }^{[30]}$ Additionally, variation of the shear strength behind the shock front with time has also been related to observations in microstructural evolution as well. ${ }^{[8,31]} \mathrm{A}$ number of techniques exist to obtain this parameter, including pressure-shear ${ }^{[32]}$ via the impact of an inclined flyer onto an inclined target assembly, the self-consistent technique ${ }^{[33]}$ where a comparison is made between a shock and release experiment to an identical shot where instead of release, a high impedance backing to the flyer launches a second shock into the target. Alternatively, since the Hugoniot stress $\left(\sigma_{x}\right)$ is offset from the hydrostatic response $(P)$ via the relation,

$$
\sigma_{x}=P+\frac{4}{3} \tau,
$$

in theory, shear strength can be determined through knowledge of both, ${ }^{[34]}$ although in practice, this is rarely done. Alternatively, if the material under investigation is considered (largely) isotropic, and assuming that the hydrostatic pressure is the average of all three orthogonal components of stress, an expression for shear strength in terms of the longitudinal and orthogonal (lateral) stresses $\left(\sigma_{y}\right)$ can be defined, thus,

$$
2 \tau=\sigma_{x}-\sigma_{y} .
$$

From this expression, it can be seen that shear strength can be measured using suitably mounted stress gages, although it is usual for the longitudinal stress to be determined from the known impact conditions. Target assemblies for lateral stress measurement are sectioned in half, and a stress gage of MicroMeasurements type J2M-SS-580SF-025 introduced some distance from the impact face. In metallic targets, $25 \mu \mathrm{m}$ of mylar is placed on either side of the gage to act as extra protection and electrical insulation. The targets are

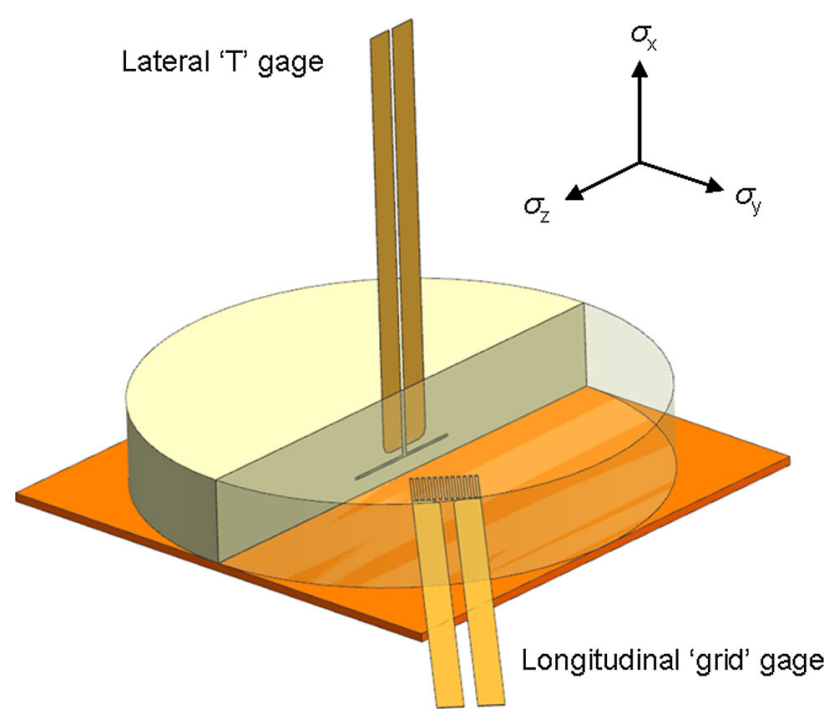

Fig. 2-Schematic of target for lateral stress measurement. The impact axis is in the $x$ direction.

reassembled using a slow setting epoxy and held in a special jig for a minimum of 1 hour. In the case of aluminum 6061, target assemblies consisted of two $60 \mathrm{~mm} \times 30 \mathrm{~mm} \times 5 \mathrm{~mm}$ thick plates, with the gage located $2 \mathrm{~mm}$ from the impact face. Impact stresses in the range 1.63 to $9.37 \mathrm{GPa}$ were generated by the impact of 5 and $10 \mathrm{~mm}$ of dural (aluminum alloy 6082-T6) and copper flyer plates at velocities of 196 to $817 \mathrm{~m} \mathrm{~s}^{-1}$. For copper-beryllium, 10-mm-thick plates, $60 \mathrm{~mm}$ by $60 \mathrm{~mm}$ square, were sectioned in half, and a stress gage introduced $4 \mathrm{~mm}$ from the front surface. Voltage - time data were converted to lateral stress - time using the methods of Rosenberg et al. ${ }^{[35]}$ An additional stress gage, MicroMeasurements type LM-SS-125CH-048 was supported on the front of the target assembly with a 1mm-thick cover plate of either dural or copper, matched to the material of the flyer plate. In this way, the longitudinal stress could also be measured, using the methods already described. The Hugoniot in terms of stress-particle velocity could also be generated via impedance matching with the known Hugoniot of the flyer plate material. ${ }^{[36]}$ Gage calibrations were according to Rosenberg et al. ${ }^{[37]}$ Longitudinal stresses in the range 2.28 to $10.7 \mathrm{GPa}$ were generated by the impact of 5- and $10-\mathrm{mm}$ flyer plates of dural and copper at velocities of 208 to $561 \mathrm{~m} \mathrm{~s}^{-1}$. A schematic diagram of a typical lateral gage assembly is shown in Figure 2.

Measurements using both HetV and stress gages will have associated errors with them. Strand et al. ${ }^{[287}$ quote errors for HetV at 1 pct, while Rosenberg et al. ${ }^{[37]}$ have indicated that the errors in gage measurements are a little higher, at 2 pct. However, additional errors will also occur, including thickness measurements, gage placements, and the small misalignments between the flyer and target plates. All these will be cumulative, but we believe that the maximum error in the results generated from these measurements will be of the order of 5 pct. 


\section{Recovery Experiments}

The experiments detailed above give time-resolved information about the mechanical evolution of the target material during shock loading. As long as the prior microstructural state of that target is known, it is possible to infer the microstructural evolution as well, but this is a poor substitute for studying the microstructure itself. While no shock loading experiment, due to the requirements of alignment, can be considered trivial, targets designed for microstructural examination have an additional level of complication. In shock loading experiments, it is convenient to assume that the target assembly is semi-infinite. In practice, the finite dimensions of the flyer and target plates will result in lateral release waves from the edges of both traveling towards the center, taking the material from a onedimensional to three-dimensional strain state. For experiments using either stress gages or interferometric methods, conditions of one-dimensional strain can be maintained for long enough at the measurement location (generally a few microseconds) that useful information can be gathered. In contrast, to determine the effects of shock loading on microstructure, the target must be loaded, released, and recovered back to ambient conditions, while at the same time maintaining conditions of purely one-dimensional strain within the region of interest. The methodology employed here uses multiple rings of material around the specimen section to trap these lateral releases from entering the specimens, based on the methods developed by Gray and colleagues. ${ }^{[38-40]}$ All recovery experiments were performed on aluminum 6061, in both the T0 and T6 conditions. To conserve material, the lateral momentum rings were made from 6082-T6, which is a near identical impedance match to 6061. After loading, the samples were decelerated into a mixture of water and cotton rags to ensure that no plastic reloading occurred and the shocked microstructure was quenched. 3-mm thick flyer plates of 6082-T6, to deliver an approximately $1 \mu \mathrm{s}$ duration pulse, were impacted at velocities of 269 and $643 \mathrm{~m} \mathrm{~s}^{-1}$, to induce stresses of 3.0 and $5.1 \mathrm{GPa}$. Once samples had been recovered, samples for transmission electron microscopy (TEM) were prepared by twin jet polishing in a solution of 10 pct (by volume) nitric acid, 90 pet methanol at $263 \mathrm{~K}, 10 \mathrm{~V}$, and $200 \mathrm{~mA}$. Samples for quasi-static mechanical testing were trepanned out of the recovered samples, such that their long axis was parallel to the shock loading axis. Sample dimensions were $2.5 \mathrm{~mm}$ diameter by $5 \mathrm{~mm}$ thick and were tested at a strain rate of $3 \times 10^{-4} \mathrm{~s}^{-1}$ (Figure 3).

\section{MATERIALS}

Aluminum 6061 is a standard age-hardened aluminum engineering alloy, and as such has received a significant degree of attention from the shock community. It was supplied in the form of $60 \mathrm{~mm} \times 30 \mathrm{~mm} \times 5 \mathrm{~mm}$ plates. These were solution treated at $823 \mathrm{~K}\left(550{ }^{\circ} \mathrm{C}\right)$ for 3 hours followed by a water quench, yielding the base line T0 condition. Half of these samples were then aged at $453 \mathrm{~K}$

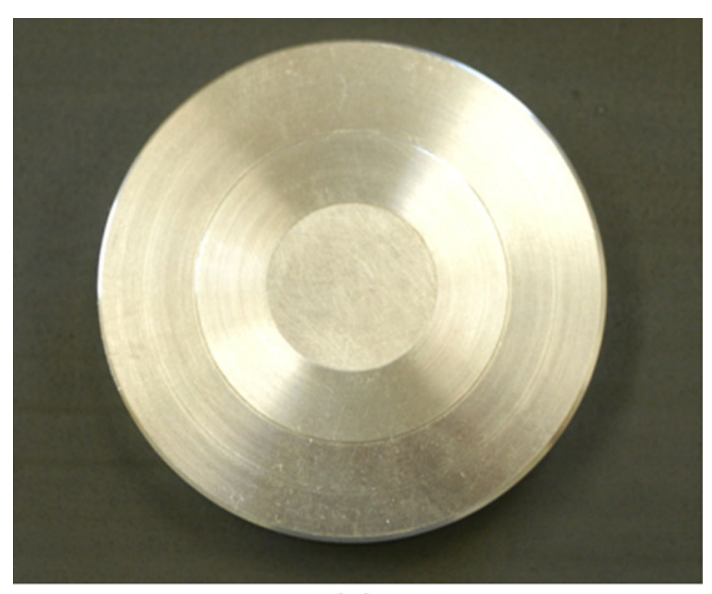

(a)

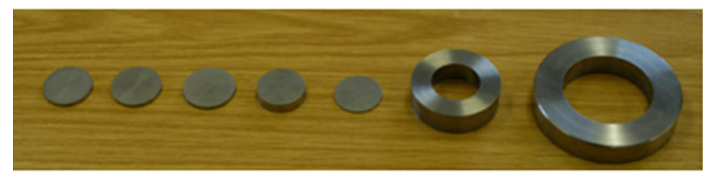

(b)

Fig. 3-Recovery target assembly. (a) Assembled target. (b) Disassembled target. The specimen itself is fourth from the left.

$\left(180{ }^{\circ} \mathrm{C}\right)$ for 8 hours with an air cool after resulting in the optimized $\mathrm{T} 6$ condition. Between target assembly and testing, the $\mathrm{T} 0$ samples were kept at $255 \mathrm{~K}\left(-18{ }^{\circ} \mathrm{C}\right)$ to prevent room temperature aging. As no obvious differences in grain size between heat treatments were observed, the matter has not been pursued.

Berylco25 referred henceforth as $\mathrm{CuBe}$ was supplied by NGK BerylcoUK Ltd, in the form of $200 \mathrm{~mm}$ diameter forged bar stock. Two separate batches were obtained; TB00 was solution treated at $1063 \mathrm{~K}\left(790{ }^{\circ} \mathrm{C}\right)$ followed by a water quench; TF00 received a subsequent aging at $602 \mathrm{~K}\left(329^{\circ} \mathrm{C}\right)$ for 3 hours. Batch to batch differences in chemistry were minor, with a minimal effect on mechanical response. The chemical composition of all three alloys is presented in Table I.

Acoustic properties were measured using $5-\mathrm{MHz}$ transducers for both longitudinal and shear measurements in pulse-echo mode, using a Panametrics PR5077 pulse receiver. The results are presented in Table II, along with the equivalent data for various similar alloys from Marsh. ${ }^{[36]}$

TEM images of aluminum 6061 as a function of heat treatment are shown in Figure 4. In the case of the T0 condition, dislocation density can be seen to be relatively low, along with a few large (approximately $300 \mathrm{~nm}$ ) intermetallic particles. These are most likely based on the composition $\mathrm{FeAl}_{6}$, due to the presence of iron as an impurity. After aging, the T6 microstructure also displays a distribution of fine precipitates $\left(\mathrm{Mg}_{2} \mathrm{Si}\right)$ as well.

Microstructural examination of $\mathrm{CuBe}$ via EBSD shows a mixture of fine recrystallized grains (of the order $40 \mu \mathrm{m}$ ) and much larger unrecrystallized grains (of the order of $\mathrm{mm}$ 's) elongated along the long axis of the original bar stock, in both heat treatments. Although it appears that the recrystallized regions are largely isotropic, the unre- 
Table I. Compositions of Materials Under Investigation (Weight Percent)

\begin{tabular}{|c|c|c|c|}
\hline & 6061 & CuBe TB00 & $\mathrm{CuBe}$ TF00 \\
\hline $\mathrm{Al}$ & bal. & 0.02 & 0.03 \\
\hline $\mathrm{Be}$ & - & 1.85 & 1.84 \\
\hline $\mathrm{Co}$ & - & 0.236 & 0.237 \\
\hline $\mathrm{Cr}$ & 0.04 to 0.35 & - & - \\
\hline $\mathrm{Cu}$ & 0.15 to 0.40 & bal. & bal. \\
\hline $\mathrm{Fe}$ & 0.7 & 0.03 & 0.03 \\
\hline $\mathrm{Mg}$ & 0.8 to 1.2 & - & - \\
\hline $\mathrm{Mn}$ & 0.15 & - & \\
\hline $\mathrm{Ni}$ & - & 0.032 & 0.008 \\
\hline $\mathrm{Pb}$ & - & 0.001 & - \\
\hline $\mathrm{Si}$ & 0.4 to 0.8 & - & - \\
\hline $\mathrm{Ti}$ & 0.15 & - & - \\
\hline $\mathrm{Zn}$ & 0.25 & - & - \\
\hline $\mathrm{Zr}$ & - & - & - \\
\hline
\end{tabular}

Table II. Acoustic, Elastic, and Mechanical Properties of the Materials Under Investigation

\begin{tabular}{|c|c|c|c|c|c|c|c|c|c|}
\hline & $\rho_{0}\left(\mathrm{~g} \mathrm{~cm}^{-3}\right)$ & $c_{\mathrm{L}}\left(\mathrm{mm} \mu \mathrm{s}^{-1}\right)$ & $c_{\mathrm{S}}\left(\mathrm{mm} \mu \mathrm{s}^{-1}\right)$ & $c_{\mathrm{B}}\left(\mathrm{mm} \mu \mathrm{s}^{-1}\right)$ & $G(\mathrm{GPa})$ & $K(\mathrm{GPa})$ & $v$ & $Y(\mathrm{MPa})$ & UTS (MPa) \\
\hline $6061 \mathrm{~T} 0$ & 2.71 & 6.27 & 3.17 & 5.09 & 27.2 & 70.2 & 0.328 & 150 & 300 \\
\hline $6061 \mathrm{~T} 6$ & 2.71 & 6.4 & 3.15 & 5.27 & 26.9 & 75.3 & 0.340 & 320 & 400 \\
\hline Al $1100^{[36]}$ & 2.7 & 6.38 & 3.16 & 5.23 & 27.0 & 73.9 & 0.337 & - & - \\
\hline Al 5083 H32 & 2.67 & 6.32 & 3.11 & 5.20 & 25.8 & 72.2 & 0.34 & 275 & 300 \\
\hline $\mathrm{CuBe}$ TB00 & 8.32 & 4.93 & 2.47 & 4.02 & 50.8 & 134.5 & 0.332 & 188 & 448 \\
\hline $\mathrm{CuBe}$ TF00 & 8.37 & 4.92 & 2.53 & 3.96 & 53.6 & 131.3 & 0.324 & 1041 & 1255 \\
\hline $\mathrm{Cu}^{[36]}$ & 8.92 & 4.78 & 2.33 & 3.95 & 48.4 & 139.2 & 0.342 & 50 & 200 \\
\hline
\end{tabular}

crystallized grains present within the microstructure will likely have introduced a degree of anisotropy into both material batches as a whole. Observations of the microstructure at finer scales were made using TEM. In both heat-treated states, only the recrystallized regions were examined. In the solution treated material, $\mathrm{CuBe}$ was observed to be a solid solution, with a low dislocation density. After aging, precipitates of size $5 \mathrm{~nm}$ diameter by 10 to $30 \mathrm{~nm}$ long were observed (Figure 5).

In Figure 6, Hugoniot data (in terms of stress and pressure vs particle velocity) are presented for both alloys. In the case of 6061, data from Marsh ${ }^{[36]}$ show close agreement between two widely different aluminum alloys, 6061 (heavily alloyed) and 1100 (commercially pure). Although it is not stated explicitly, we believe that the 6061 data would have been taken from an aged material. However, the similarity between these two alloys is such that we are confident that any differences between the heat-treated states of 6061 would be minimal, and hence the Hugoniot data presented by Marsh will be used in all subsequent considerations. In contrast, for $\mathrm{CuBe},{ }^{[27]}$ it can be seen that considerable differences occur between the two heat-treated states, with the aged material showing a stiffer response. This is a first indication that precipitation hardening has a much greater response in $\mathrm{CuBe}$ than it does in 6061.

\section{RESULTS}

Lateral stress traces from aluminum 6061 are presented in Figure 7, in both the T0 and T6 conditions.
Observe that there are significantly different behaviors between the two material states. In the case of the solution treated material, the initial rises in the shock front are extremely rapid, faster in fact than the gauge can respond. This leads (in the case of the higher amplitude shots) to an electrical overshoot which is explained more fully elsewhere. ${ }^{[41]}$ Compare this to the much slower rises in the T6 condition where no electrical overshoot is detected. In both heat treatments, lateral stress appears to decrease slightly over a period of approximately $500 \mathrm{~ns}$, suggesting that shear strength (from Eq. [5]) (and thus by implication microstructure) is evolving over this time period. Such behavior although more pronounced has also been observed in nickel and its alloys. ${ }^{[8]}$

Where lateral stress reaches its steady value, it has been used (along with the known impact stress) to determine the shear strength. The results are presented in Figure 8. The straight line fit has been determined via

$$
2 \tau=\frac{1-2 v}{1-v} \sigma_{x},
$$

where $v$ is the appropriate value of Poisson's ratio (see Table II). In practice, only the value for the solutiontreated state has been used as using the aged value produces a near identical result. It would appear that there is little variation between the two heat-treated states, except for perhaps the lowest amplitude shot, where the T6 result lies on the calculated elastic response.

This result is somewhat surprising as at quasi-static strain rates this heat treatment regime should achieve 


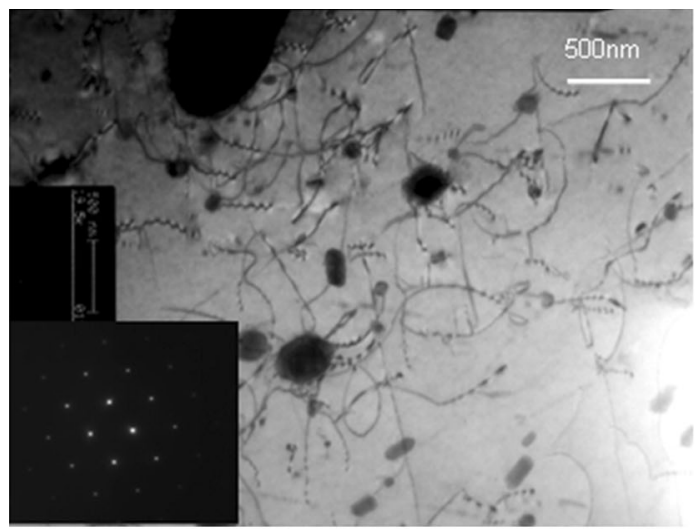

(a)

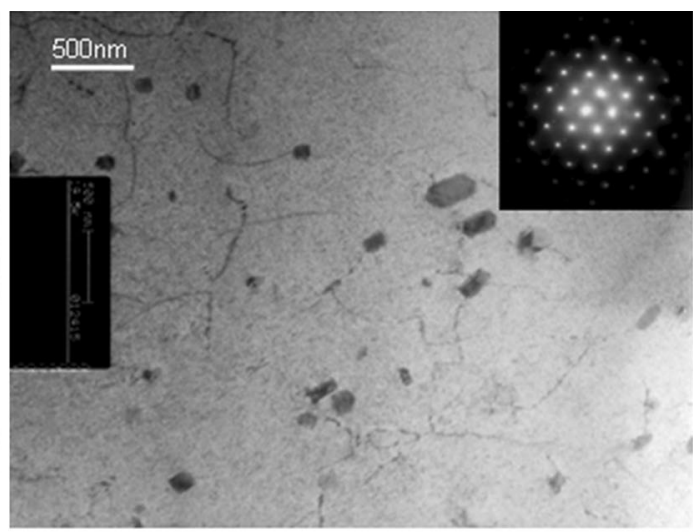

(b)

Fig. 4-Transmission Electron Micrographs of as received microstructures of aluminum 6061. (a) Solution treated (T0); (b) Aged (T6). In both micrographs, $g=11 \overline{1}$ and $\mathrm{B}=[101]$.

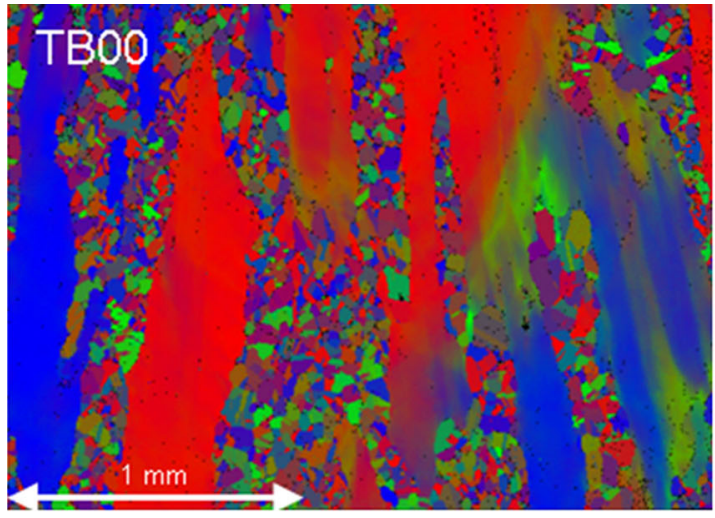

(a)

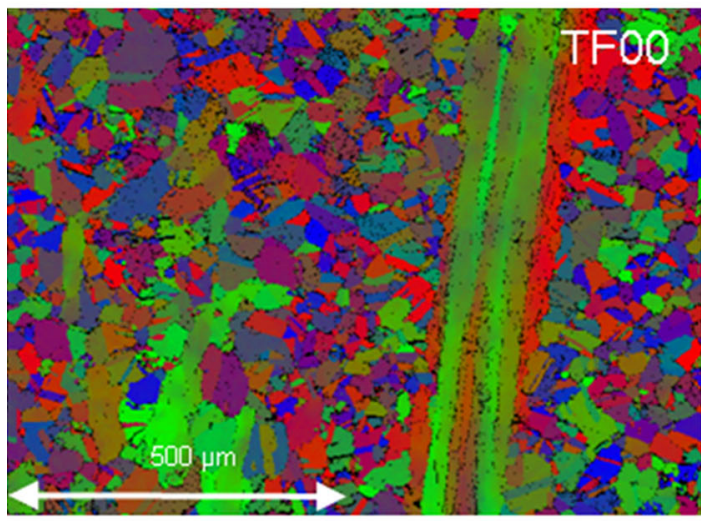

(c)

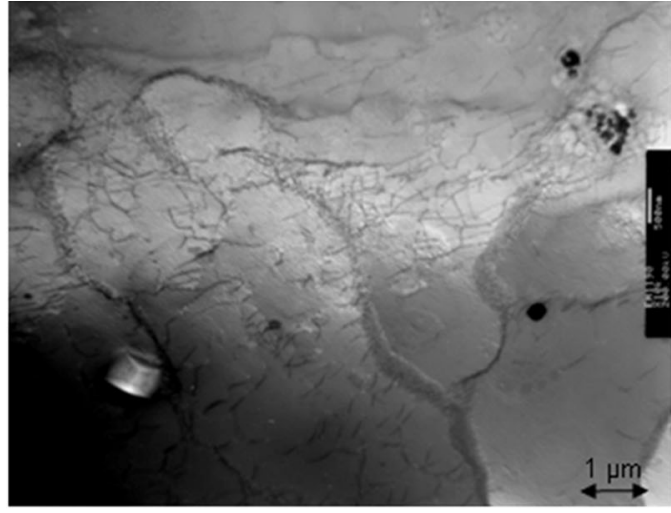

(b)

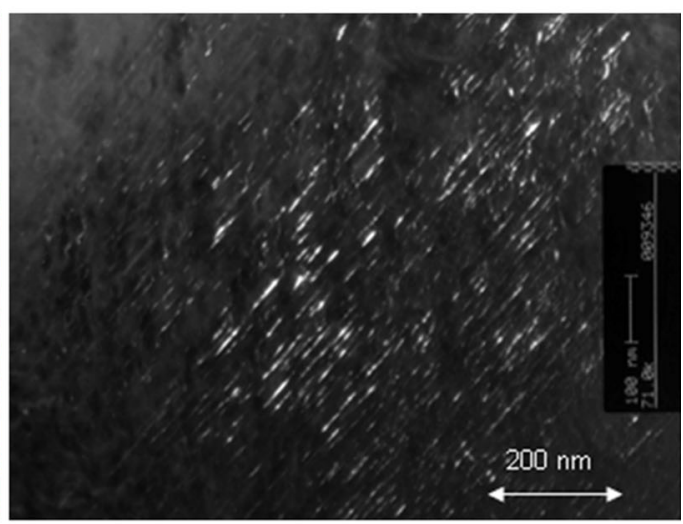

(d)

Fig. 5-Micrographs of as received solution-treated and aged CuBe. (a) EBSD solution treated; (b) TEM solution treated (bright field); (c) EBSD aged; (d) TEM aged (dark field).

significant increases in strength in the aged material. In an effort to answer these questions, samples of 6061 in both heat-treated states were shocked and recovered using the techniques discussed in the previous section. The TEM specimens were taken from the central region of the recovered samples, with the axis of observation being orthogonal to the loading axis. The results are shown below. In Figure 9, shocked and recovered microstructures (at 3 and 5.1 GPa for a pulse duration of ca. $1 \mu \mathrm{s})$ are presented for both heat-treated states. In the T0 (solution treated) state, the microstructure consists of a loose dislocation cell structure, which appears to decrease in cell size somewhat as impact stress increases. In contrast, in the T6 condition, the 


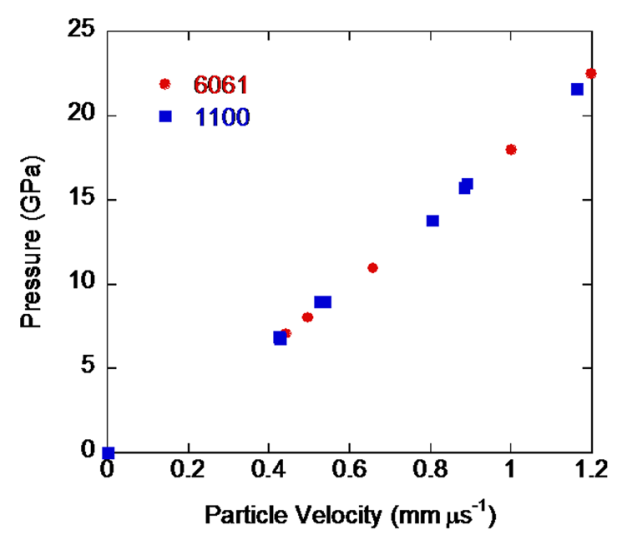

(a)

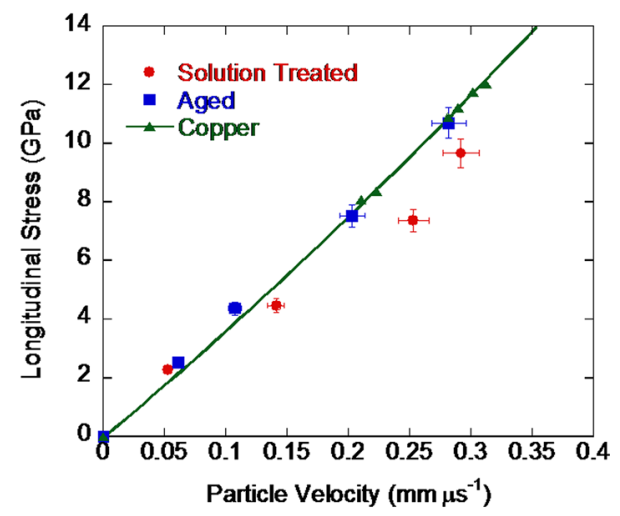

(b)

Fig. 6-Hugoniots in Pressure/Stress-particle velocity space. ${ }^{[27,36]}$ (a) Aluminum alloys; (b) Copper-beryllium alloy.

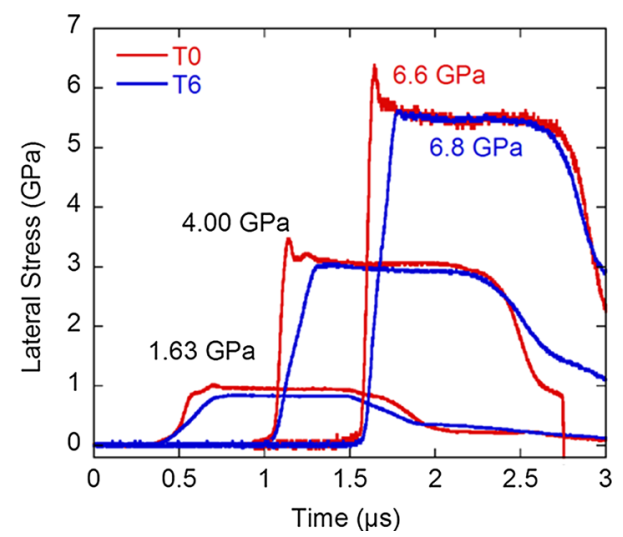

Fig. 7-Lateral stress gage traces for aluminum 6061. The traces are labeled with the impact stresses.

dislocation structure is much more randomized (no obvious cell structure), although some planar features are also present.

Given the differences between the shocked microstructures, it would be expected that the post-shock mechanical behavior would also be different as well. The results are presented in Figure 10.

Note that the stress-strain curves for the recovered material have been displaced along the strain axis by the residual strain imposed by the shock and release

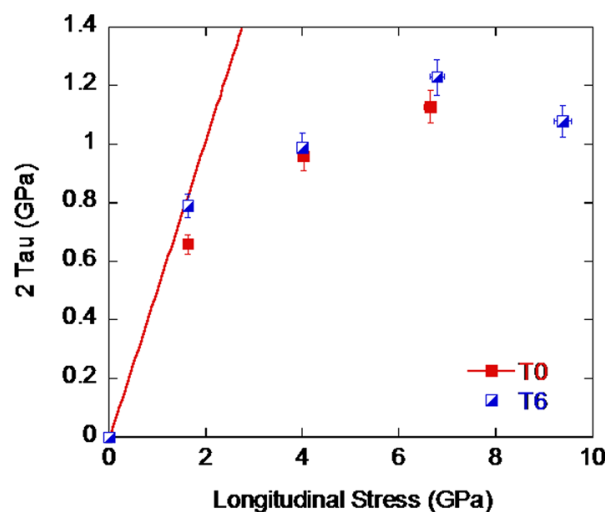

Fig. 8-Variation of shear strength with impact stress as a function of heat treatment in aluminum 6061. The straight line fit is the elastic response calculated using Eq. [4] and the appropriate value of Poisson's ratio.

processes. This can be calculated through consideration of the effective (or in the case of this series of experiments residual) strain, $\varepsilon_{\text {res }}$, as discussed in, ${ }^{[3]}$ where,

$$
\varepsilon_{\text {res }}=\frac{\sqrt{2}}{3}\left[\left(\varepsilon_{x}-\varepsilon_{y}\right)^{2}+\left(\varepsilon_{x}-\varepsilon_{z}\right)^{2}+\left(\varepsilon_{y}-\varepsilon_{z}\right)^{2}\right]^{1 / 2},
$$

$\varepsilon$ is the natural strain and the subscripts $x, y$, and $z$ refer to the orthogonal directions with $x$ the impact axis. As all deformations occur under one-dimensional strain, the $y$ and $z$ components are zero, and thus the residual strain reduces to

$$
\varepsilon_{\text {res }}=\frac{2}{3} \varepsilon_{x} .
$$

However, this only covers the loading part of the cycle; if we assume that a similar strain occurs on release, the residual strain doubles. Further, from the conservation relations, the longitudinal strain can be calculated as the natural logarithm of the volumetric strain ( $v_{0}$-ambient and $v$-shocked specific volumes), and then the total residual strain after shock loading becomes,

$$
\varepsilon_{\mathrm{res}}=\frac{4}{3} \ln \left[\frac{V}{V_{0}}\right] .
$$

In the $\mathrm{T} 0$ condition, it is clear that the material has undergone considerable shock-induced hardening. In contrast, the T6-aged material, there is no evidence of any hardening at all.

Lateral stress traces from $\mathrm{CuBe}$ are presented in Figure 11.

As with aluminum 6061, there appears to be a reduction in lateral stress behind the shock front, this time over a period up to $1 \mu \mathrm{s}$. Also observe that in common with the previous material, the rising part of the shock front is considerably faster in the solution treated, rather than the aged conditions.

In Figure 12, results show that in contrast to the Al $6061, \mathrm{CuBe}$ is considerably stronger under shock loading in the aged condition compared to the solution 


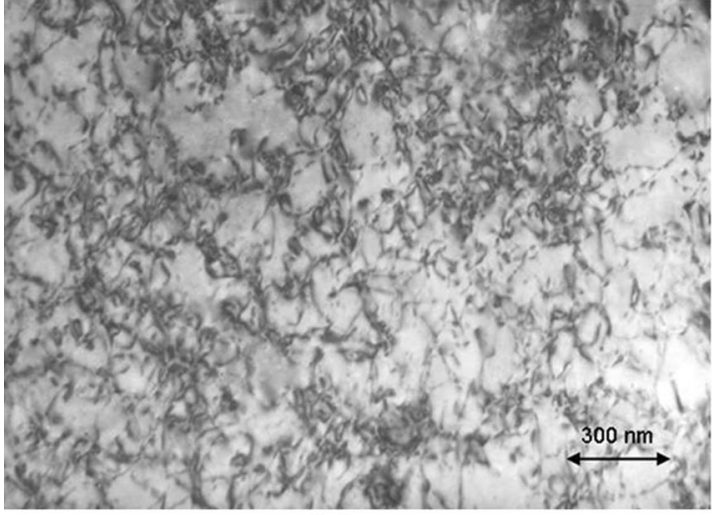

(a)

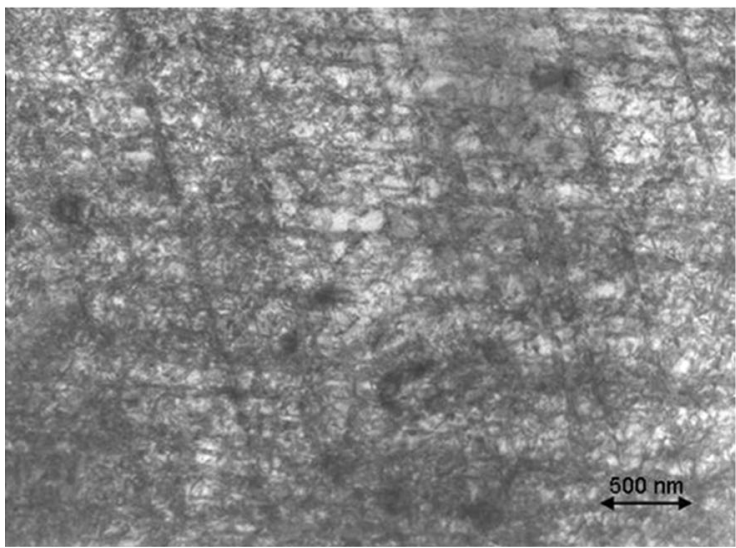

(c)

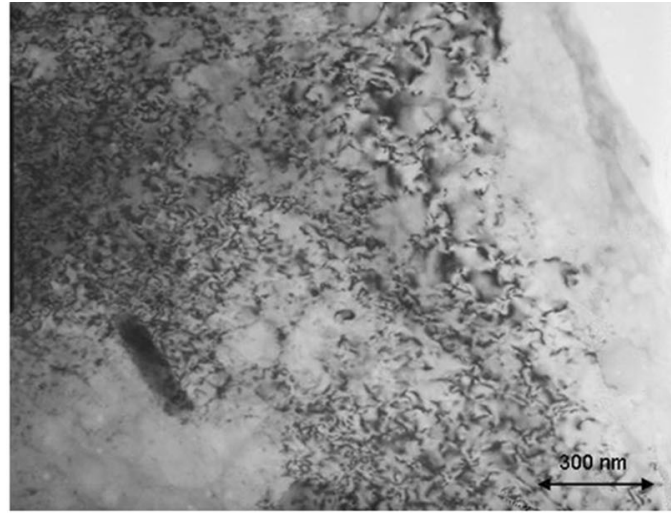

(b)

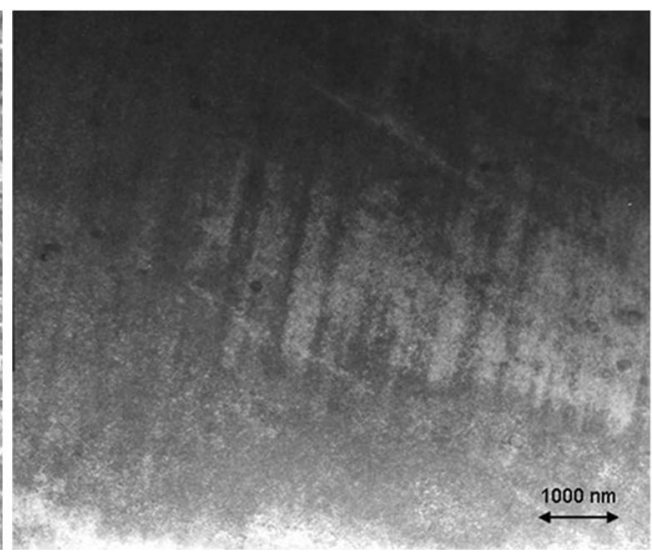

(d)

Fig. 9-Shocked micrographs of shocked and recovered aluminum 6061 . The pulse width was approximately $1 \mu$ s. $(a)$ T0 3.0 GPa; $(b)$ T0 $5.1 \mathrm{GPa} ;(c)$ T6 $3.0 \mathrm{GPa}$; (d) T6 5.1 GPa.

treated. However, it is interesting to note that the ageinduced strengthening is of the order $\times 2$, while at quasistatic strain rates, the equivalent strengthening is in excess of $\times 5$. Also observe that the shear strengths of the solution-treated material are near identical to that of pure copper. ${ }^{[42]}$ This result is somewhat unexpected, given that the large differences in dimension between beryllium and copper atoms would be expected to induce large lattice strains as beryllium substitutes for copper.

Free surface velocity measurements of $\mathrm{CuBe}$ have also been investigated, with typical results as shown in Figure 13.

Both traces are qualitatively similar, showing a rise up to the maximum velocity amplitude of ca. $0.3 \mathrm{~mm} \mu \mathrm{s}^{-1}$, for a period of approximately $0.75 \mu$ s before partially releasing and reloading, indicating that the material has undergone at least partial tensile failure (spall). Observe that as with the lateral stress gage traces, the rise time of the solution-treated materials is significantly faster than that of the aged. In both states, there is also a break in slope (labeled HEL) which signifies the Hugoniot Elastic Limit (the yield stress under conditions of shock induced one-dimensional strain). Although it is less clearly defined in the aged state, it is still significantly greater than in the solution-treated material. It is determined through the relation,

$$
H E L=\rho_{0} c_{L} \frac{u_{\mathrm{fse}}}{2},
$$

where $u_{\text {fse }}$ is the free surface velocity at the break in slope. In the solution-treated state, this yields an HEL of $1.06 \pm 0.09 \mathrm{GPa}$, while in the aged state, the HEL has increased to $3.12 \pm 0.24 \mathrm{GPa}$; although as stated previously, the more diffuse nature of the elastic plastic separation of the shock front results in a greater error. Note that the aged trace is significantly more noisy than the corresponding solution-treated state. We believe that this is due to fluctuating light levels on the return from the rear surface.

The drop in free surface velocity after passage of the main shock is also used to determine the spall (tensile) strength of the material under investigation. Qualitatively, it is clear that this drop is greater in the aged condition, indicating that the spall strength is greatest in this state. However, this can be quantified by determination of the one-dimensional fracture stress, $\sigma_{F}$, taking into account changes in impedance, ${ }^{[43]}$

$$
\sigma_{F}=\rho_{0}\left(u_{1}-u_{F}\right)\left[c_{0}+S\left(u_{1}-u_{F}\right)\right]
$$




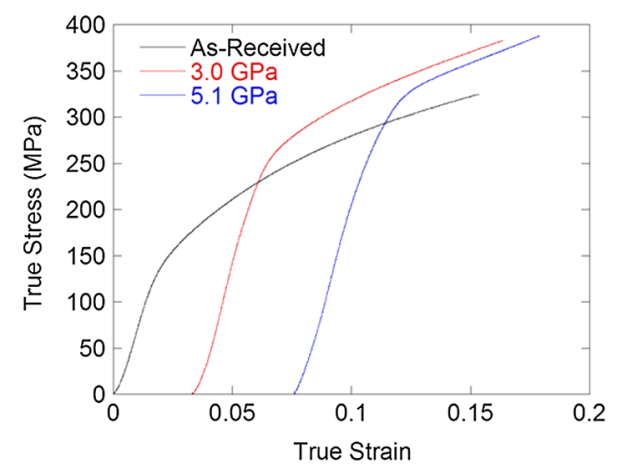

(a)

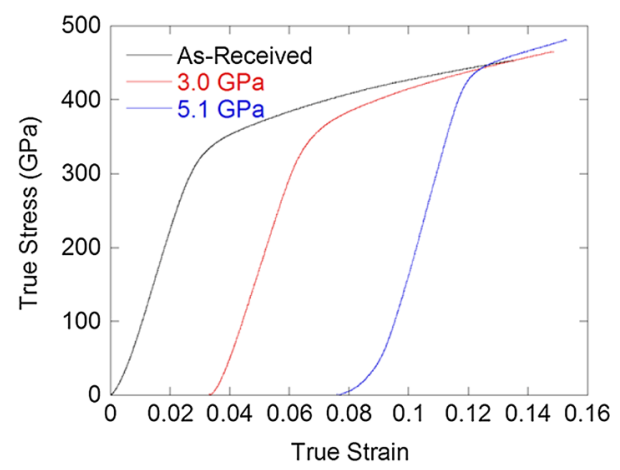

(b)

Fig. 10-Post-shock mechanical response of aluminum 6061. (a) Solution treated (T0); (b) Aged (T6).

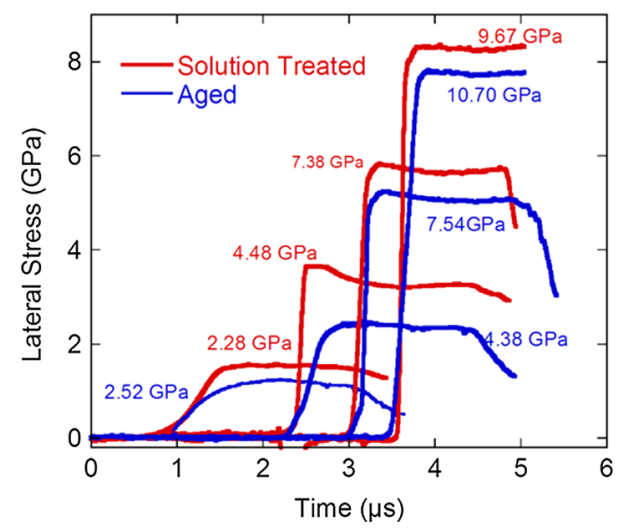

Fig. 11-Lateral stress histories in $\mathrm{Cu}-2 \mathrm{Be}$. Each trace is labeled with the impact stress.

where

$u_{F}=\frac{1}{2}\left[-\left(\frac{c_{0}}{S}\right)+\left\{\left(\frac{c_{0}}{S}\right)^{2}+2\left[\left(\frac{c_{0}}{S}\right)\left(u_{1}+u_{2}\right)+\left(u_{1}^{2}+u_{2}^{2}\right)\right]\right\}^{1 / 2}\right]$,

and $u_{1}$ and $u_{2}$ are the maxima and minima at the first dip (see Figure 13). However, it has also been pointed out that the reload part of the signal is attenuated as it passes through the scab, ${ }^{[44]}$ hence the actual spall strength, ${ }^{[45]} \sigma_{\text {spall }}$, is,

$$
\sigma_{\text {spall }}=\sigma_{F}-\Delta \sigma,
$$

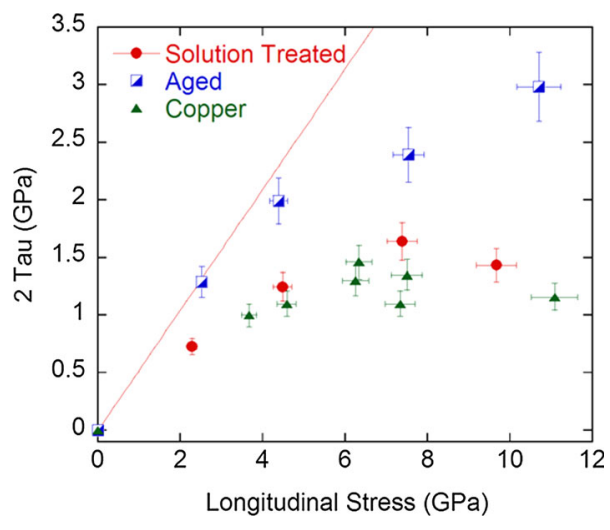

Fig. 12 - Shear strength in CuBe. The straight line fit is according to Eq. [6], using the appropriate Poisson's ratio.

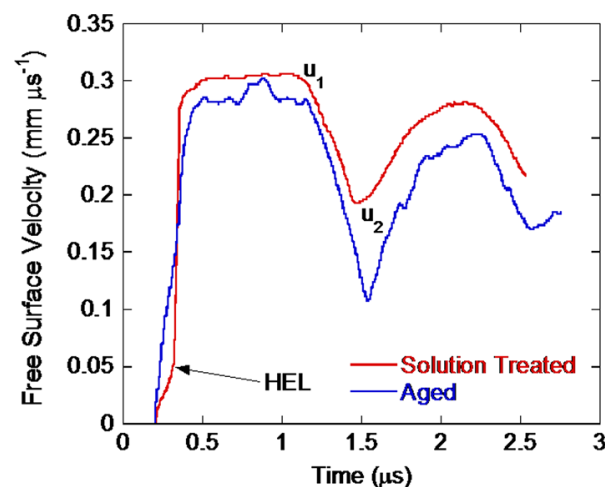

Fig. 13-Free surface velocity traces for $\mathrm{CuBe}$, at an impact stress of $5.3 \mathrm{GPa}$.

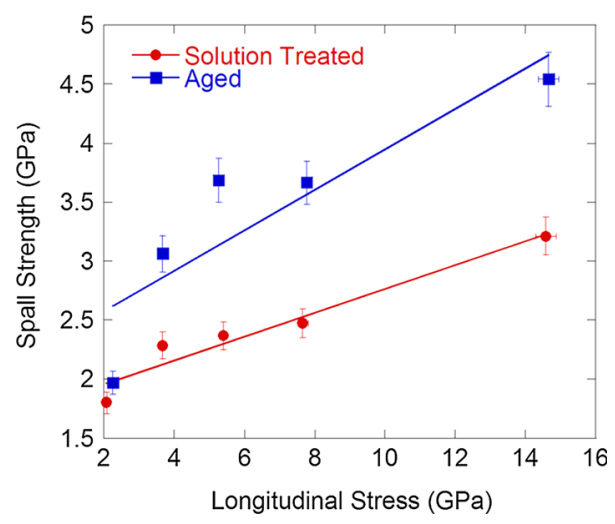

Fig. 14-Spall strength $v s$ impact stress for $\mathrm{CuBe}$ as a function of heat treatment.

where,

$$
\Delta \sigma=\frac{h}{2} \frac{d P}{d t}\left(\frac{1}{c_{B}}-\frac{1}{c_{L}}\right),
$$

with $\mathrm{d} P / \mathrm{d} t$ being the slope of the initial part of the release and $c_{\mathrm{B}}$ and $c_{\mathrm{L}}$ the bulk and longitudinal sound speeds, respectively. Spall strength $v$ s longitudinal stress is shown in Figure 14. 
Table III. Summary of Experimental Conditions and Results

\begin{tabular}{|c|c|c|c|c|c|c|c|}
\hline Flyer (mm) & Impact Velocity $\left(\mathrm{mm} \mu \mathrm{s}^{-1}\right)$ & Target $(\mathrm{mm})$ & $u_{\mathrm{p}}\left(\mathrm{mm} \mu \mathrm{s}^{-1}\right)$ & $\sigma_{x}(\mathrm{GPa})$ & $\sigma_{\text {spall }}(\mathrm{GPa})$ & HEL (GPa) & $2 \tau(\mathrm{GPa})$ \\
\hline \multicolumn{8}{|c|}{ Al 6061 Lateral Gage Experiments } \\
\hline $\mathrm{Al}, 10$ & 200 & $\mathrm{~T} 0,5$ & $0.111(\mathrm{a})$ & 1.63 & - & - & 0.66 \\
\hline $\mathrm{Al}, 10$ & 500 & T0, 5 & $0.260(\mathrm{a})$ & 4.02 & - & - & 0.96 \\
\hline $\mathrm{Cu}, 10$ & 587 & T0, 5 & 0.415 (a) & 6.64 & - & - & 1.13 \\
\hline $\mathrm{Al}, 5$ & 196 & T6, 5 & $0.111(\mathrm{a})$ & 1.63 & - & - & 0.79 \\
\hline $\mathrm{Al}, 5$ & 497 & $\mathrm{~T} 6,5$ & $0.260(\mathrm{a})$ & 4.0 & - & - & 0.99 \\
\hline $\mathrm{Cu}, 10$ & 600 & $\mathrm{~T} 6,5$ & $0.426(\mathrm{a})$ & 6.78 & - & - & 1.23 \\
\hline $\mathrm{Cu}, 10$ & 817 & T6, 5 & $0.568(\mathrm{a})$ & 9.37 & - & - & 1.08 \\
\hline \multicolumn{8}{|c|}{ Al6061 Recovery Experiments } \\
\hline $\mathrm{Al}, 3$ & 269 & T0 & 0.199 (a) & 3.0 & - & - & - \\
\hline $\mathrm{Al}, 3$ & 643 & T0 & 0.327 (a) & 5.1 & - & - & - \\
\hline $\mathrm{Al}, 3$ & 269 & T6 & 0.199 (a) & 3.0 & - & - & - \\
\hline $\mathrm{Al}, 3$ & 643 & T6 & 0.327 (a) & 5.1 & - & - & - \\
\hline \multicolumn{8}{|c|}{ CuBe Lateral Gage Experiments } \\
\hline $\mathrm{Al}, 10$ & 211 & TB00, 10 & 0.053 & 2.28 & - & - & 0.73 \\
\hline $\mathrm{Al}, 10$ & 421 & TB 00,10 & 0.141 & 4.48 & - & - & 1.25 \\
\hline $\mathrm{Cu}, 5$ & 445 & TB 00,10 & 0.253 & 7.38 & - & - & 1.64 \\
\hline $\mathrm{Cu}, 5$ & 549 & ТВ 00,10 & 0.292 & 9.67 & - & - & 1.43 \\
\hline $\mathrm{Al}, 10$ & 208 & $\mathrm{TF} 00,10$ & 0.061 & 2.52 & - & - & 1.29 \\
\hline $\mathrm{Al}, 10$ & 395 & TF00, 10 & 0.107 & 4.38 & - & - & 1.99 \\
\hline $\mathrm{Cu}, 5$ & 400 & TF00, 10 & 0.203 & 7.54 & - & - & 2.39 \\
\hline $\mathrm{Cu}, 5$ & 561 & TF00, 10 & 0.282 & 10.7 & - & - & 2.98 \\
\hline \multicolumn{8}{|c|}{ CuBe Spall Experiments } \\
\hline $\mathrm{Al}, 3.36$ & 193 & ТВ00, 5 & 0.062 & 2.09 & 1.80 & 0.97 & - \\
\hline $\mathrm{Al}, 3.36$ & 333 & TB00, 5 & 0.114 & 3.67 & 2.28 & 1.20 & - \\
\hline $\mathrm{Al}, 3.36$ & 502 & ТВ00, 5 & 0.172 & 5.40 & 2.37 & 1.05 & - \\
\hline $\mathrm{Cu}, 2.5$ & 427 & ТВ00, 5 & 0.242 & 7.67 & 2.47 & 1.01 & - \\
\hline $\mathrm{Cu}, 2.5$ & 750 & TB00, 5 & 0.382 & 14.58 & 3.21 & 1.05 & - \\
\hline $\mathrm{Al}, 3.36$ & 203 & TF00, 5 & 0.063 & 2.25 & 1.97 & 3.22 & - \\
\hline $\mathrm{Al}, 3.36$ & 333 & TF00, 5 & 0.101 & 3.67 & 3.06 & 2.81 & - \\
\hline $\mathrm{Al}, 3.36$ & 497 & TF00, 5 & 0.143 & 5.28 & 3.69 & 3.19 & - \\
\hline $\mathrm{Cu}, 2.5$ & 425 & TF00, 5 & 0.206 & 7.77 & 3.67 & 3.43 & - \\
\hline $\mathrm{Cu}, 2.5$ & 742 & TF00, 5 & 0.368 & 14.66 & 4.54 & 2.96 & - \\
\hline
\end{tabular}

(a) particle velocity calculated using impedance matching methods, using the published data of Marsh. ${ }^{[40]}$

As with both the HELs and shear strength, $\mathrm{CuBe}$ shows a significant level of strengthening as the material is aged, although at between $\times 2$ and 2.5 , this is still less than the levels of strengthening seen at quasi-static stress levels. A summary of experimental conditions and results is presented in Table III.

\section{DISCUSSION}

The results in this report have shown that the expected changes in shock-induced mechanical properties due to age hardening (as indicated by their quasi-static equivalents) have not manifest, either being near zero (6061) or only increasing by a factor of ca. 2 to $3(\mathrm{CuBe})$. In contrast, the shocked microstructures and post-shock mechanical properties have (in this case only studied in 6061 although we would expect similar results in $\mathrm{CuBe}$ ) been shown to be significantly altered by the aging process, with significant dislocation generation (relaxing into a cell structure on release) and a high degree of postshock strengthening in the solution-treated T0 condition, compared to a more randomized dislocation distribution (along with evidence of planar dislocation arrays) in the aged T6 state. Finally, it has also been noted that in all gage and rear surface HetV traces, the rise time is much faster in the solution-treated state than the aged (for both 6061 and $\mathrm{CuBe}$ ). Clearly, the answers lie in the shockinduced microstructures. In the case of $6061 \mathrm{~T} 0$, the dislocation cell structure has been observed in other aluminum alloys, including pure aluminum, ${ }^{[5,25]}$ and in a wider context, other face-centerd cubic metals with moderate to high stacking fault energies, ${ }^{[4,6,46]}$ and thus the observed behavior is to be expected. In contrast, the microstructural observations from the T6 condition show a more randomized distribution of dislocations, indicating that the presence of precipitates has altered their generation and motion from the T0 state. Similar results were observed between pure and TD nickel (hardened with a dispersion of thoria particles) by Murr et al. ${ }^{[16]}$ who again noted that the presence of non-shearable particles transitioned the recovered microstructure from one dominated by dislocations cells to a more random microstructure. Although no recovery work has been performed upon $\mathrm{CuBe}$, it would seem likely that the aged material is behaving in a similar manner. Therefore, it would appear that the presence of a fine distribution of particles within the microstructure has the effect of both impeding their motion under load and hindering their generation in the first place. This is manifest in the longer rise times in the aged material when compared to the solution-treated state. However, there still remains the 
question as to why the age-induced increases in strength observed at quasi-static strain rates are not observed (at least to the same extent) during shock loading. Again, it is believed that the answer can be found in the recovered microstructures. It has already been shown that the presence of precipitates has a significant effect upon the operative mechanisms of plasticity. If, as has been suggested, precipitates impede both the formation and motion of dislocations, then it is possible that the strainrate sensitivity of the material itself is effected, being lower in the aged condition. If so, due to the large increases in strain-rate between quasi-static and shock-induced deformation, it is likely that the strength of the solution-treated state effectively catches up with that of the aged, in the 6061 reducing the difference to zero, and in the $\mathrm{CuBe}$, reducing the differences from around 5 at quasi-static strain-rates to around 2 under shock loading.

Finally, from Figure 12, it can be seen that the shear strength of $\mathrm{CuBe}$ in the solution-treated state is almost identical (over a similar impact stress range) to that of pure copper. Under quasi-static conditions (Table II), it can be seen that the introduction of $2 \mathrm{wt}$ pct beryllium in solid solution to copper increases both yield and tensile strength from 50 to $188 \mathrm{MPa}$ and 200 to $448 \mathrm{MPa}$, respectively. The large differences in atomic radii of copper $(128 \mathrm{pm})$ and beryllium $(112 \mathrm{pm})$ will result in large lattice strains as beryllium substitutes onto the copper lattice, further resulting in the significant levels of strengthening seen at quasi-static strain rates. It would also be expected that such effects would also influence the mechanisms of plasticity, including dislocation motion and generation, and propensity to twin. Twin formation has been shown to reduce both in situ shear strength in nickel alloys ${ }^{[8]}$ and post-shock strengthening (accounting for imposed shock pre-strain) in copper-aluminum alloys. ${ }^{[10-12]}$ Given the effect of dilute alloying of aluminum in copper (reducing SFE from ca. 78 to $6 \mathrm{~mJ} \mathrm{~m}^{-2}$ at $6 \mathrm{wt}$ pct), it might be expected that the presence of beryllium to have a similar effect. Nordstrom et al., ${ }^{[24]}$ in an investigation of the shock response of a copper-1.91 wt pet beryllium alloy, indicated that the SFE of this alloy was in the range 30 to $70 \mathrm{~mJ} \mathrm{~m}{ }^{-2}$. From Eq. [1], this suggests that the level of partial dislocation separation is in the range 5 to 10 Burger's vectors, compared to approximately 5 for copper. While this further suggests that twinning is more likely in $\mathrm{CuBe}$, it is not to the same extent as in copper-aluminum alloys. Again, Nordstrom et al. ${ }^{[24]}$ did notice a small amount of twinning in recovered samples, but only at shock stresses of $20 \mathrm{GPa}$ and above. Twinning is also affected by other factors, including grain size and dislocation density. For example, Meyers et $a{ }^{\left[{ }^{[4]}\right.}$ explosively loaded copper to $50 \mathrm{GPa}$, showing that a material with a grain size of ca. $315 \mu \mathrm{m}$ twinned heavily, while with a grain size of $9.5 \mu \mathrm{m}$ under identical loading conditions, no twinning was observed. In the case of the copper data presented in Figure 12, the reported grain size was ca. $15 \mu \mathrm{m},{ }^{[42]}$ impacted to a maximum stress of $11 \mathrm{GPa}$, suggesting that no twinning occurred. The slightly larger recrystallised grain size in $\mathrm{CuBe}$ (36 to $44 \mu \mathrm{m}$ ), combined with the lower SFE (than copper) determined by Nordstrom et al. ${ }^{[24]}$ would suggest that this material will have a slightly more likelihood to twin. Therefore, we present a tentative hypothesis concerning the shock response of solutiontreated $\mathrm{CuBe}$. It is believed that there are in fact two competing deformation mechanisms in operation. Firstly, there is a twining response that reduces the overall shear strength behind the shock front. Such behavior has been observed previously in a nickel60 wt pet cobalt alloy, where the shear strength was significantly lower than the parent nickel. ${ }^{[8]}$ Recovery of both showed that the alloy had significant levels of deformation twins, with none in the pure metal. Further, similarities in the atomic radii of nickel and cobalt suggest that solution strengthening would have had little contribution, lending further credence to twinning reducing shock-induced strengthening. In contrast, in $\mathrm{CuBe}$, the large differences in atomic radii would result in large lattice strains, which will now significantly affect the mechanical behavior, and potentially counteract the strength reductions caused by twinning. However, we point out that no microstructural analysis has be performed on $\mathrm{CuBe}$ so at present, these results can only be treated as a working hypothesis.

\section{CONCLUSIONS}

The effects of age hardening on the shock response of two materials, the engineering aluminum alloy 6061 and a copper-2 wt pet beryllium alloy $(\mathrm{CuBe})$ have been investigated in terms of shock-induced microstructures and post-shock mechanical properties (6061 only), shear strength (6061 and $\mathrm{CuBe}$ ), and HEL and spall strength ( $\mathrm{CuBe}$ only). While clear differences in microstructure, post-shock mechanical response and shock rise times were observed, the expected differences in in situ mechanical response were not observed. In solution-treated 6061, the shocked microstructure was observed to consist of a network of dislocation cells, indicating that in common with other high stacking fault energy, face-centered cubic metals, deformation was dominated by the motion and generation of dislocations. Correspondingly, the postshock mechanical properties also showed that the shocked material experienced significant hardening due to the passage of the shock wave through the target. In contrast, the aged material showed a dislocation structure that was much more randomized, and that post-shock mechanical properties showed no evidence of hardening at all. This lead to the suggestion that the presence of fine precipitates throughout the microstructure hinders both the passage and generation of dislocations. Further evidence was noted in the rise times of the lateral stress gage traces, where this was longer in the aged material than the solution treated. Similar observations were made in the rise times of both the lateral stress traces and free surface velocity traces in $\mathrm{CuBe}$, and it was suggested for the same reasons, although in this material no microstructural observations were made. However, as has already mentioned, the large differences in strength seen at quasi-static strain rates did not manifest to the same extent under shock loading conditions. In the case of 6061, shear strengths in both heat treated conditions were 
observed to be near identical. In $\mathrm{CuBe}$, aging did induce a significant degree of strengthening under shock loading, but this increase was only by a factor of 2 to 2.5 , rather than the factor of 5 seen at quasi-static levels. Again, it is believed that this is due to the precipitates hindering the motion and generation of dislocations. Therefore, it would seem likely that due to the reduced level of dislocation activity in the aged state, the strain-rate sensitivity will also be lower compared to the solutiontreated material, thus allowing the mechanical properties in that state to approach those in the aged state. Finally, it was also noted that the shear strength of solution-treated $\mathrm{CuBe}$ was almost identical to that of pure copper. It has been suggested that this would be due to competition of two different mechanisms; firstly, that a degree of shockinduced twinning reduces the overall strength but is countered by the large differences in atomic radii between copper and beryllium that results in a high degree of solution strengthening that increases overall strength. However, at this point, it is acknowledged that no recovery experiments in $\mathrm{CuBe}$ have been undertaken, and so at present, this remains hypothetical.

\section{ACKNOWLEDGMENTS}

The author would like to thank the following for their assistance in this program - Glenn Whiteman, Nigel Park, Sue Ennaceur from AWE, Rusty Gray from Los Alamos National Laboratories, Andy Roberts and Gareth Appleby-Thomas from Cranfield Defence and Security, Ian Jones and Ming Chu from the University of Birmingham, and Neil Bourne from the University of Manchester. (C) British Crown Owned Copyright 2014/AWE. Published with permission of the Controller of Her Britannic Majesty's Stationery Office. "This document is of United Kingdom origin and contains proprietary information which is the property of Secretary of State for Defence. Such information may not be copied or used in whole or in part without prior written consent of Defence Intellectual Property Rights DGDCDIPRPL- Ministry of Defence, Abbey Wood, Bristol, BS348JH, England."

\section{REFERENCES}

1. M.A. Meyers: Dynamic Behavior of Materials, Wiley, New York, 1994.

2. N. Bourne: Materials in Mechanical Extremes, Cambridge University Press, Cambridge, Fundamentals and Applications, 2013.

3. R.E. Smallman: Modern Physical Metallurgy, Butterworths, London, 1985.

4. G.T. Gray III and C.E. Morris: J. de Phy. IV , 1991, vol. Colloque C3, pp. 191-96.

5. G.T. Gray, III and J.C. Huang: Mater. Sci. Eng., 1991, vol. A145, pp. 21-35.

6. P.S. Follensbee and G.T. Gray, III: Int. J. Plast, 1991, vol. 7, pp. $651-60$.

7. L.E. Murr, O.T. Inal, and A.A. Morales: Acta Metall., 1976 , vol. 24 , pp. $261-70$.

8. J.C.F. Millett, N.K. Bourne, and G.T. Gray, III: Metall. Mater. Trans. A, 2008, vol. 39A, pp. 322-34.

9. L.E. Murr and D. Kuhlmann-Wilsdorf: Acta Metall., 1978, vol. 26, pp. 847-57.
10. A. Rohatgi and K.S. Vecchio: Mater. Sci. Eng., 2002, vol. A328, pp. 256-66.

11. A. Rohatgi, K.S. Vecchio, and G.T. Gray, III: Metall. Mater. Trans. A, 2001, vol. 32A, pp. 135-45.

12. A. Rohatgi, K.S. Vecchio, and G.T. Gray, III: Acta Mater., 2001, vol. 49, pp. 427-38

13. B.H. Sencer, S.A. Maloy, and G.T. Gray, III: Acta Mater., 2005, vol. 53, pp. 3293-303

14. Q. Xue, G.T. Gray, III, B.L. Henrie, S.A. Maloy, and S.R. Chen: Metall. Mater. Trans. A, 2005, vol. 36A, pp. 1471-86.

15. J.C.F. Millett, G. Whiteman, and N.K. Bourne: J. Appl. Phys., 2009, vol. 105 , p. 033515.

16. L.E. Murr, H.R. Vydyanath, and J.V. Foltz: Metall. Trans., 1970, vol. 1, pp. 3215-23.

17. G.R. Fowles: J. Appl. Phys., 1961, vol. 32, pp. 1475-87.

18. J.R. Asay, T. Ao, J.-P. Davis, C. Hall, T.J. Vogler, and G.T. Gray, III: J. Appl. Phys., 2008, vol. 103, p. 083514

19. X. Chen, J.R. Asay, S.K. Dwivedi, and D.P. Field: J. Appl. Phys., 2006, vol. 99, p. 023528.

20. H. Huang and J.R. Asay: J. Appl. Phys., 2005, vol. 98, p. 033524.

21. Z. Rosenberg, G. Luttwak, Y. Yeshurun, and Y. Partom: J. Appl. Phys., 1983, vol. 54, pp. 2147-52.

22. S. Yadav, D.R. Chichili, and K.T. Ramesh: Acta Metall. Mater., 1995, vol. 43, pp. 4453-64.

23. G.T. Gray III: in High-Pressure Shock Compression of Solids, J. R. Asay and M. Shahinpoor, eds., Springer, New York, 1991, pp. $187-215$.

24. T.V. Nordstrom, R.W. Rohde, and D.J. Mottern: Metall. Trans. A, 1975, vol. 6A, pp. 1561-68.

25. G.T. Gray, III: Acta Metall., 1988, vol. 36, pp. 1745-54.

26. J.C.F. Millett, N.K. Bourne, M.Q. Chu, I.P. Jones, G.T. Gray, III, and G. Appleby-Thomas: J. Appl. Phys., 2010, vol. 108, p. 073502.

27. J.C.F. Millett, G. Whiteman, N.T. Park, S. Case and G. ApplebyThomas: Acta Mater., 2013, In press.

28. O.T. Strand, D.R. Goosman, C. Martinez, T.L. Whitworth, and W.W. Kuhlow: Rev. Sci. Instrum., 2006, vol. 77, p. 083108.

29. L.M. Barker and R.E. Hollenbach: J. Appl. Phys., 1970, vol. 41, pp. $4208-26$.

30. L.W. Meyer, F.J. Behler, K. Frank and L.S. Magness: in 12th Int. Symp. Ballistics, eds., San Antonio, Texas, 1990, pp. 419-28.

31. G.T. Gray, III, N.K. Bourne, and J.C.F. Millett: J. Appl. Phys., 2003, vol. 94, pp. 6430-36.

32. M. Zhou and R.J. Clifton: J. Appl. Mech., 1997, vol. 64, pp. 487-94.

33. H. Huang and J.R. Asay: J. Appl. Phys., 2007, vol. 101, p. 063550.

34. D.P. Dandekar and W.J. Weisgerber: Int. J. Plast., 1999, vol. 15, pp. 1291-309.

35. Z. Rosenberg, N.K. Bourne, and J.C.F. Millett: Meas. Sci. Technol., 2007, vol. 18, pp. 1843-47.

36. S.P. Marsh: LASL Shock Hugoniot Data, University of California Press, Los Angeles, 1980

37. Z. Rosenberg, D. Yaziv, and Y. Partom: J. Appl. Phys., 1980, vol. 51, pp. 3702-05.

38. G.T. Gray III: in Shock Compression of Condensed Matter-1989, S.C. Schmidt, J.N. Johnson and L.W. Davison, eds., North-Holland, Amsterdam, 1990, pp. 407-14.

39. G.T. Gray III: in Shock-wave and High-strain-rate Phenomena in Materials, M.A. Meyers, L.E. Murr and K.P. Staudhammer, eds., Marcel Dekker, New York, 1992, pp. 899-911.

40. N.K. Bourne and G.T. Gray, III: Proc. R. Soc. A, 2005, vol. 461, pp. $3297-312$.

41. N.K. Bourne and Z. Rosenberg: Meas. Sci. Tecchnol., 1997, vol. 8, pp. 570-73.

42. J.C.F. Millett, N.K. Bourne, and Z. Rosenberg: J. Appl. Phys., 1997, vol. 81, pp. 2579-83.

43. G.R. Gathers: Selected Topics in Shock Wave Physics and Equation of State Modeling, World Scientific, Singapore, 1994.

44. V.I. Romanchenko and G.V. Stepanov: Zhur. Prik. Mekh. Tekh. Fiz., 1980, vol. 4, p. 141.

45. L.C. Chhabildas, L.M. Barker, J.R. Asay, and T.G. Trucano: Int. J. Impact Eng., 1990, vol. 10, pp. 107-24.

46. M.A. Meyers, H.J. Kestenbach, and C.A.O. Soares: Mater. Sci. Eng., 1980, vol. 45, pp. 143-52.

47. M.A. Meyers, U.R. Andrade, and A.H. Chokshi: Metall. Mater. Trans. A, 1995, vol. 26A, pp. 2881-96. 